\title{
Aplikasi Pengacak Soal Ujian Berkategori Menggunakan Metode LCM (Linear Congruent Method)
}

1) Yoseph Juli Christopher Sitanggang

STMIK Budi Darma Medan, JI. Sisingamangaraja No. 338 Medan, Sumatera Utara, Indonesia E-Mail: joes.gusar@gmail.com

\section{2) Tonni Limbong}

UNIKA ST. Thomas SU, JI. Setiabudi No 479 F Tanjungsari, Meda, Sumatera Utara, Indonesia E-Mail : tonni.budidarma@gmail.com

\begin{abstract}
ABSTRAK
Ujian adalah tes yang bertujuan untuk menentukan kemampuan seorang murid, mahasiswa atau calon pekerja. Biasanya ujian tes bentuknya tertulis, walaupun beberapa mungkin praktek atau komponen praktis, dan sangat bervariasi dalam struktur, isi dan kesulitan tergantung pada subjek, kelompok usia orang yang diuji dan profesi. Namun tidak jarang juga terjadinya kecurangan seperti kebocoran soal yang sering dilakukan oleh panitia. Soal ujian yang disajikan kepada para peserta ujian dan dalam pencapian hasil yang optimal maka perlu menyajikan soal ujian dalam bentuk pengelompokan/kategori seperti : Mudah, Sedang, Sulit dan dalam pelaksanaan ujian akan dilakukan pengacakan dan akan dilakukan cetak secara langsung di dipan para peseta uji untuk menghindari terjadinya kebocoran. Sistem aplikasi yang digunakan untuk mengacak $\mathbb{N}$ soal-soal ujian tersebut dengan menggunakan metode-metode pengacakan yang tersedia. Linear Congruent Method (LCM) adalah sebuah metode pengacakan yang masih belum sempurna karena masih memunculkan angka yang sama sehingga dibutuhkan metode Resuffle dan Rejection Method.
\end{abstract}

\section{Keyword : Soal Ujian, Aplikasi Pengacakan Soal, Linear Congruent Method}

\section{PENDAHULUAN}

Saat ini dalam dunia pendidikan sangat berhubungan dengan perkembangan teknologi, baik pendidikan formal maupun informal, terutama pada perguruan tinggi. Dalam perkembangan teknologi yang serba komputer banyak yang masih ketinggalan dalam teknologi tersebut khususnya teknologi komputer, padahal teknologi komputer selalu dilibatkan dalam pendidikan seperti memberikan materi menggunakan komputer dan ujian menggunakan komputer.

Soal ujian berkategori adalah soal yang akan dibagi-bagi menjadi beberapa kategori seperti Mudah, Sedang, Sulit yang akan diterapkan di dalam soal-soal ujian sehingga peserta ujian tidak akan mengetahui soal yang akan dijawab, dan di setiap kategori akan ada tingkat kesulitan ujian ${ }^{[6,10]}$.

Metode LCM (Linear Congruent Method) Bilangan acak yang dibangkitkan oleh komputer merupakan bilangan acak semu, karena pembangkitannya menggunakan operasi-operasi aritmatika. Banyak algoritma atau metode yang dapat digunakan untuk membangkitkan bilangan acak. Di dalam buku teks statistik klasik, angka-angka acak diciptakan dengan mengambil bola yang dinomori ke luar dari suatu kotak yang berisi sejumlah bola bernomor yang diketahui jumlahnya ${ }^{[1]}$.

Adapun rumusan masalah yang akan dibahas dalam penelitian ini adalah :

1. Bagaimana melakukan pengacakan soal ujian agar terhindar dari pembocoran soal?

2. Bagaimana mengimplementasikan metode LCM pada pengacakan soal ujian berkategori?

3. Bagaimana merancang perangkat lunak pengacakan soal ujian berkategori dengan metode LCM?

Bilangan acak merupakan suatu besaran dasar dalam modeling dan teknik-teknik simulasi. Pada modeling dan simulasi banyak sekali memanfaatkan bilangan acak sebagai besaran untuk mendapatkan penyelesaian suatu permasalahan simulasi.

Untuk mendapatkan bilangan yang benar-benar acak, secara manual dapat dilakukan dengan menggunakan undian, arisan, atau pemakaian mesin roullete. Tetapi secara komputasi, hal ini sulit dilakukan. Hal ini disebabkan bahwa komputer merupakan mesin deterministik, sedangkan bilangan acak muncul sebagai kejadian yang probabilistic. Satu-satunya cara untuk mendapatkan bilangan acak adalah 
dengan meng-gunakan pseudo random generator (pembangkit bilangan acak semu), dimana bilangan acak diperoleh secara deterministik (aritmatik) ${ }^{[2]}$.

Metode Linear Congruent ini sangat banyak digunakan untuk membangkitkan bilangan acak $r 1, r 2, \ldots, r n$ yang bernilai $[0, m]$ dengan memanfaatkan nilai sebelumnya. Untuk membangkitkan bilangan acak ke $n+1 \quad\left(r_{n+1}\right)$ dengan metode Linear Congruent, didefinisikan:

$r_{n+1}=\left(a r_{n}+c\right) \bmod m$

dimana a,c dan $\mathrm{m}$ dinamakan nilai pembangkit, r0 dinamakan nilai awal, biasanya nilai ini yang di-gunakan dalam proses randomize (mengacak di awal atau state awal).

Contoh : Misalkan ditentukan $a=4, c=1$ dan $r 1=3$, maka bilangan acak $0 \mathrm{~s} / \mathrm{d} 8(m=9)$ dapat dihitung:

$\mathrm{r} 2=((4)(3)+1) \bmod 9=4$

$\mathrm{r} 3=((4)(4)+1) \bmod 9=8$

$\mathrm{r} 4=((4)(8)+1) \bmod 9=6$

dan seterusnya ${ }^{[6]}$.

\section{METODE PENELITIAN}

Pengacakan soal ujian berkateogri dilakukan agar terhindar dari kebocoran soal yang sering dilakukan oleh panitia. Dengan melakukan pengacakan soal ujian berkategori maka nanti soal-soal yang ada akan diacak secara otomatis dan akan menghasilkan soal yang sudah teracak sehingga soal tersebut akan di cetak langsung di depan para peserta agar terhindar terjadinya kebocoran soal.

Menentukan pengacakan soal berkategori menggunakan metode Linear Congruent Method adalah dengan menggunakan rumus $X=(a \cdot x+b) \bmod M$ pada aplikasi yang akan digunakan dengan keterangan $\mathrm{X}=$ bilangan acak ke-i, $a=$ faktor penggali, $x=$ bilangan acak sebelumnya, $b=$ increment, dan $M=$ Modulus. Dengan membangkitkan rumus maka akan dapat hasil pengacakan soal tanpa adanya soal yang sama muncul kembali ${ }^{[7]}$.

Data yang diperoleh akan dianalisis sesuai dengan kebutuhan dan keadaan data untuk pemanfaatan. Analisis ini meliputi mengidentifikasikan dan mengevaluasi permasalahan, kesempatan, hambatan yang terjadi dan kebutuhan yang diharapkan sehingga dapat diusulkan perbaikan. Permasalahan yang ditemukan dasar perancangan sistem yang dikembangkan. yaitu untuk mengacak soal ujian dengan type dokumen microsoft Word tanpa menginput soal dalam bentuk database.

Sebelum melakukan perancangan terhadap perangkat lunak ujian menggunakan metode linear congruent method (LCM) ini, penulis melakukan analisa terhadap metode tersebut agar dapat diimplementasikan pada bahasa pemrograman yang penulis gunakan. Dalam membangkitkan bilangan acak pada visual basic 2008 maka diperlukan rumus yang dapat membuat soal-soal yang berkategori diacak supaya nantinya tidak ada soal yang sama muncul pada peserta ujian lainnya.

LCM memanfaatkan model linier untuk membangkitkan bilangan acak yang didefinisikan sebagai berikut $X=(a \cdot x+b$ ) $\bmod M$

$$
\begin{aligned}
\text { Dimana }: & X=\text { bilangan acak } k e-i \\
& a=\text { Faktor Penggali } \\
& x=\text { bilangan acak sebelumnya } \\
& b=\text { increment } \\
& M=\text { Modulus }
\end{aligned}
$$

Sebagai Contoh, untuk mengacak bilangan sebanyak 8 kali, di mana nilai $a=11$, $b=25, m=26$ dan $X(0)=3$ adalah sebagai berikut 1.

1. $L(1)=(11(3)+25) \bmod 26=6$

2. $\quad X(2)=(11(6)+25) \bmod 26=13$

3. $X(3)=(11(13)+25) \bmod 26=12$

4. $\quad X(4)=(11(12)+25) \bmod 26=1$

5. $\quad X(5)=(11(1)+25) \bmod 26=10$

6. $X(6)=(11(10)+25) \bmod 26=21$

7. $\quad X(7)=(11(21)+25) \bmod 26=22$

8. $\quad X(8)=(11(22)+25) \bmod 26=11$

9. $X(8)=(11(11)+25) \bmod 26=16$

10. $X(8)=(11(16)+25) \bmod 26=19$ adalah :

Maka, bilangan acak yang dibangkitkan

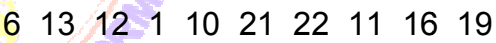

Dari contoh diatas dapat diketahui bahwa dalam pembangkitan bilangan acak tidak terjadi perulangan.

Setelah melakukan analisa terhadap sistem perangkat lunak yang akan dirancang, selanjutnya dilakukan perancangan terhadap perangkat lunak tersebut. Adapun tahapan perancangan yang dilakukan meliputi perancangan proses, dan perancangan antar muka program.

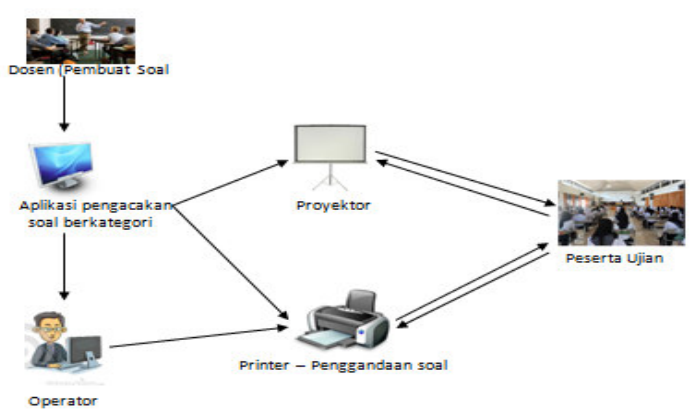

Gambar 1 Perancangan interface pengacakan soal berkategori 
Berdasarkan hasil analisa masalah yang dilakukan sebelumnya, penulis merancang proses kerja ujian menggunakan metode LCM untuk melakukan import file soal, melaukan pengacakan dan menyimpan kembali file soalsoal yang telah diacak. Adapun bentuk rancangan proses kerja perangkat lunak ini adalah :

\section{Alur Kerja Sistem Use Case}

Di bawah ini adalah contoh Use Case pada perancangan Program sebagaimana terlihat pada gambar 2 dibawah ini.

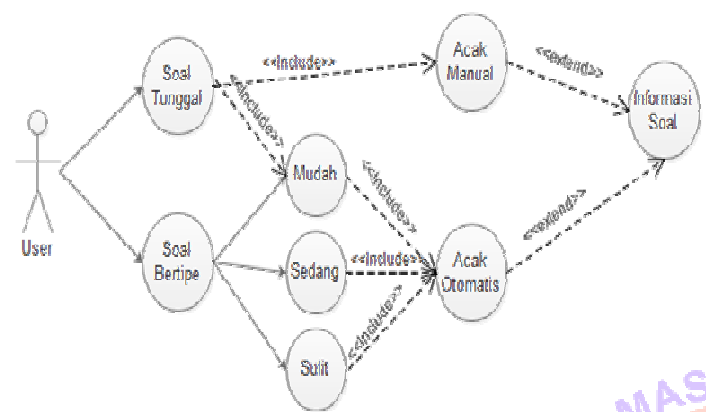

Gambar 2. Use Case Aplikasi pengacakan soal berkategori

2. Alur Kerja Sistem UML

Di bawah ini adalah contoh Use Case dan UML pada perancangan Program sebagaimana terlihat pada gambar 3. dibawah ini.

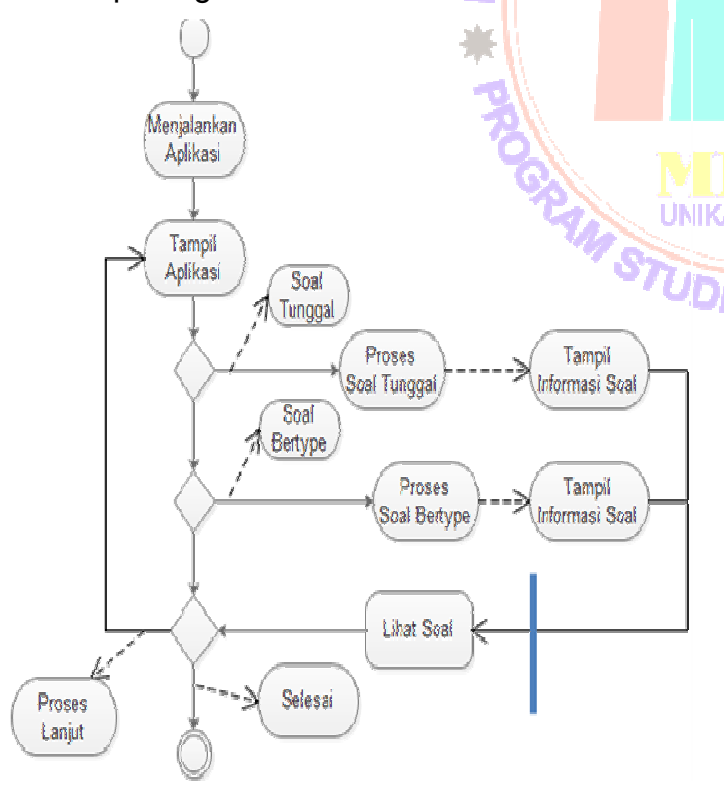

Gambar 3 UML Aplikasi Pengacakan soal berkategor

Dari perancangan sistem yang dibahas pada dituangkan dalam algoritma untuk pembuatan script program, yang bertujuan untuk menghasilkan tampilan antar muka (User
Interface) dan hasil proses sistem (Sistem Process). Pada sub bab ini diuraikan algoritma untuk pembuatan kode script yang utama, yang merupakan inti dari proses dari sistem ${ }^{[4]}$.

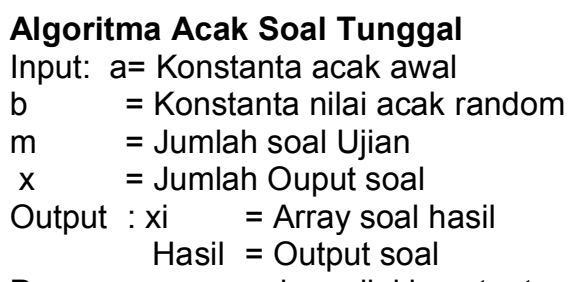

Proses : $a=$ masukan nilai konstanta acak awal

$$
\begin{aligned}
& B=\text { masukan nilai random awal } \\
& \text { For } i=1 \text { to } x \text { do } \\
& x i=(a * x+b) \text { mod } m \\
& \text { then } \\
& \text { if } i=0 \\
& x i=x i+1 \\
& \text { end if } \\
& x=x i \\
& \text { hasil }=x i
\end{aligned}
$$

\section{HASIL DAN PEMBAHASAN}

Implementasi sistem program ini mencakup spesifikasi kebutuhan perangkat keras (Hardware) dan spesifikasi perangkat lunak (Software).

\section{Spesifikasi Perangkat Keras dan Perangkat Lunak}

Program ini direkomendasikan untuk dijalankan dengan menggunakan perangkat keras (hardware) yang mempunyai spesifikasi sebagai berikut :

Aplikasi Pengacak Soal Berkategori Menggunakan Metode LCM (Linear Congruent Method) Oleh : ${ }^{1)}$ Yoseph Juli Christoper Sitanggang, ${ }^{2)}$ Tonni Limbong 
1. Prosesor minimal Pentium IV

2. Memory minimal $1 \mathrm{~GB}$

3. Harddisk minimal $80 \mathrm{~GB}$

4. VGA Card $64 \mathrm{MB}$

5. Monitor dengan resolusi $800 \times 600$ pixel

6. Keyboard dan Mouse

Adapun perangkat lunak (Software)

yang akan digunakan untuk menjalankan aplikasi ini adalah :

1. Sistem Operasi Windows 7 ultimate 32 Bit

2. Program Aplikasi Microsoft Visual Basic 2008

3. Microsoft Office Word 2007

\section{Pengujian Program}

1. Menu Utama Tampilah menu utama

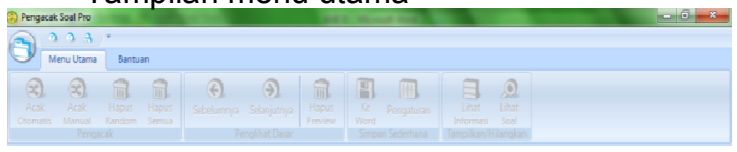

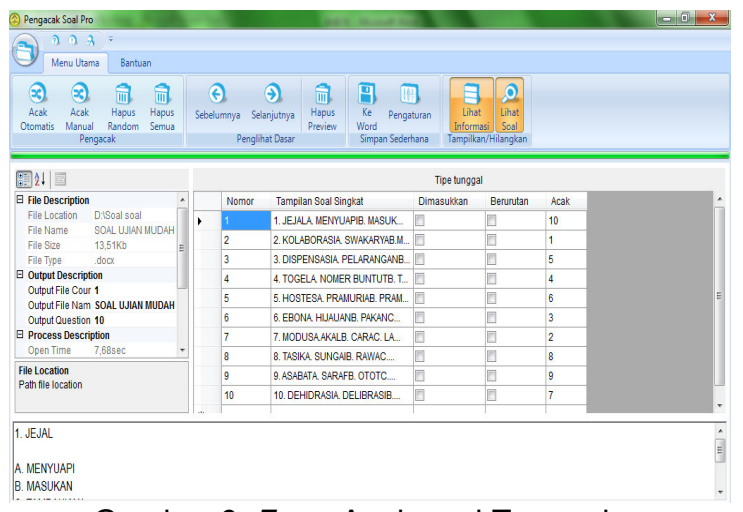

Gambar 6. Form Acak soal Tunggal

\section{KESIMPULAN}

Adapun Kesimpulan dari penelitian ini adalah :

1. Soal ujian harus diacak tiap saat pelaksanaan ujian agar soal berbeda dari soal sebelumnya sehingga peserta ujian harus benar-benar memiliki persiapan yang baik pada saat ujian.

2. Linear Congruent Method diterapkan untuk mengacak soal yang terbuat dari microsoft word dengan nilai awal acak soal sebagai konstanta a, nilai dari random sebagai variabel $\mathrm{b}$ dan $\mathrm{m}$ adalah jumlah soal yang ada baik itu soal tunggal ataupun soal berkategori. Proses pengacakan dengan metode LCM harus ditambah dengan beberapa kondisi untuk menghindari hasil angka 0 dan angka yang sama.

3. Merancang aplikasi pengacakan soal berkategori dengan Microsoft Visual Basic 2008 terdiri dari form menu utama, form menu pilihan, form acak soal tunggal, form acak soal berkategori, form pengaturan, form menyimpan ke microsoft word, dan form bantuan. adalah:

Adapun saran dari penulisan penelitian ini

1. Diharapkan ada metode Resuffle untuk menghindari soal yang sama muncul kembali untuk menggantikan kondisi yang dipakai pada aplikasi ini.

2. Jumlah soal ujian di banksoal harus lebih banyak dari pada jumlah soal yang akan dikeluarkan atau dicetak.

3. Saat pencetakan di microsoft word khususnya untuk soal bertipe/berkategori disarankan menemukan sebuah metode yang langsung dapat memberikan penomoran secara berurut di microsoft word untuk soal yang akan dicetak, setelah dilakukan pengacakan.

4. Pengembangan sistem berikutnya diharapkan merancang aplikasi ujian 
berbasis online yang didalamnya ada pengacakan soal.

\section{DAFTAR PUSTAKA}

1. Abdul Kadir \& Terra Ch. Triwahyuni, Pengenalan Teknologi Informasi, Andi, Jakarta, 2003

2. Bambang Haryanto, Rekayasa Perangkat Sistem Berorientas Objek, Informatika Bandung, Jakarta, 2010

3. Jogiyanto, Kamus Komputer, Rineka Cipta Jakarta, 2004

4. Jogiyanto, Analisa Dan Perancangan Sistem Informasi, 2005

5. Ketut Darmayuda, Pemrograman Aplikasi Database dengan Visual Basic.Net 2008, Penerbit Informatika, 2010

6. Tonni Limbong, Janner Simarmata, Implementasi Linear Congruent Method (LCM) Untuk Pengacakan Soal Ujian Berkategori, Proceedings Seminar Nasional IImu Komputer (SNIKOM) 2015

7. http://www.haryanto/pengertianpengacakan-soal/, diakses 23 April 2016

8. http://www.ipulhe.com/pengertian-aplikasi diakses 15 Maret 2016

9. http://www.totalinfo.or.id, diakses 15 Maret 2016

10. http://www.totalinfo.or.id/pengertian-ujian, diakses 15 Maret 2016 